\title{
POR UMA FANEROLOGIA DAS IMAGENS III O MAPA, A TERRA E A MIGRAÇÃO DAS IMAGENS
}

\author{
Eduardo Jorge de Oliveira \\ UNICAMP/FAPESP
}

RESUMO: 0 objetivo desse texto é ler uma recomposição de mapas em uma cartografia artística e literária, posicionando a ficção entre as noç̃oes de profecia e de ausência, determinando outras inscrições temporais de obra a partir de Nelson Félix. A ficção, a partir do eixo do espaço, reinventa os mapas realizados a partir do modelo gráfico, movimentando-se por textos literários, filosóficos e pelas coordenadas geográficas que reinventam a superfície do mundo, isto é, seus traços contidos nas suas peles, suas imagens.

PALAVRAS-CHAVE: Mapa. Terra. Ficção. Ausência. Pele do Mundo.

\section{FOR A PHANEROLOGY OF IMAGES III MAP, LAND AND IMAGE MIGRATION}

ABSTRACT: The purpose of this text is to make a lecture of a composition of maps in an artistic and literary cartography; to study their fictional position between prophecy and notions of absence. Those aspects will be determining for Nelson Felix's artwork. The fiction, from the axis of space, in this perspective the maps come from the graph model, they are reinvented from literary, philosophical texts and geographical positions. They reinvent the surface of the world, they contains in the surface of the skin, their images.

KEYWORDS: Map. Land. Fiction. Absence. Skin of the world.

Eduardo Jorge de Oliveira é pós-doutorando em Literatura na Universidade Estadual de Campinas. 


\title{
POR UMA FANEROLOGIA DAS IMAGENS III O MAPA, A TERRA E A IMIGRAÇÃO DAS IMAGENS ${ }^{1}$
}

\author{
Eduardo Jorge de Oliveira
}

\section{O MAPA E SEUS LUGARES MAIS INFRA-ORDINÁRIOS}

A cultura costuma responder às questões da vida pelo equívoco. Esse é o grau de exterioridade que cria um campo de forças que compõe um lugar exterior ao qual ela, em busca de respostas, consegue desvencilhar-se da armadilha binária onde geralmente ela é posta diante da natureza para formar, assim, uma oposição. Uma falsa oposição. Por esse equívoco o estilo põe a vida à prova e com ele passamos a identificar assinaturas dentro do ambiente cultural. Nessa dinâmica, cada frase torna-se um prolongamento da fisiologia do corpo que a redigiu, assim como a pontuação da respiração. Em termos de composição essas forças se organizam de modo semelhante, pelo desenho, pela pintura, pela escultura, enfim, pela expressão ou pelo modo de se retirar para deixar ali as marcas do real. Por esse viés, a escrita, a partir de seus erros, enfim, torna-se um modo de tatear o mundo e, seguramente, multiplicar as formas e modos de vida.

A partir de uma ramificação complexa como essa brevemente descrita, um texto desenvolve-se cartograficamente como um mapa, sobretudo por historiar internamente o pensamento, à luz de uma história das ideias oscilantes entre natureza e cultura. Nela existem linhas cronológicas que delimitam os encontros que onde essas formas sociais passaram a emergir, resultando, assim, em imagens. Imagens que sempre parecem pedir para ser decifradas de imediato por intuições. Por interpretações que podem ser precisas ou dispersas, fracas ou insustentáveis. Entre essas iniciativas, o cruzamento histórico

\footnotetext{
${ }^{1}$ Esse ensaio resulta da tese de doutorado Inventar uma pele para tudo. Texturas da animalidade na literatura e nas artes visuais (Uma incursão na obra de Nuno Ramos a partir de Georges Bataille), defendida em cotutela entre o Programa de Pós-graduação em Teoria Literária e Literatura Comparada da Universidade Federal de Minas Gerais (UFMG) e o Departamento de Filosofia da Ecole Normale Supérieure (ENS), em Paris, sob a orientação de Maria Esther Maciel (UFMG) e Dominique Lestel (ENS). A pesquisa foi desenvolvida com bolsa da Capes, no Brasil e em Paris. Ele faz parte de um livro em curso sobre a fanerologia das imagens.
} 
que as separam não merece ser desprezado. E a História, por fim, constitui um modo temporário de organizar o mundo natural, levando em consideração um ethos da vida social que resultou em imagem, mantendo no mundo ocidental suas raízes com o sagrado - do marco zero da era cristã até o extremo da sua secularização, a catástrofe do progresso, anunciada por Walter Benjamin, a partir da análise detalhada da imagem do anjo de Paul Klee. Esse é apenas um aspecto do sagrado, provavelmente o mais legível em termos de cultura de texto e o que permite entender os limites da secularização. Talvez por esse aspecto que o sagrado tenha religado de modo tão intenso esses polos cultura e natureza, relegando o que mimetiza mais ou menos o mundo natural pelo viés do humano incompleto, não civilizado ou mesmo sob o signo da animalidade.

O resultado dessa polarização não aconteceria sem embate. E com isso as imagens seriam um nó visível dessa linha que merece ser lida sob o aspecto profético. Precisamos de um grau de profecia, de adivinhação, de arqueologia, dos arquivos e de gestos para interpretarmos o que não é transmissível. Mesmo a história da arte, seu texto ou, melhor, sua narrativa pode ser entendida como uma história de profecias. Para isso, ela necessita ser descrita do ponto de vista do presente imediato, o que reúne sua atualidade e inatualidade simultaneamente. Com essa característica, Walter Benjamin reconhece uma intransmissibilidade em cada época, por isso, algumas vezes, ler imagens também partilha do tom profético de leituras de fígado de um cordeiro, como atesta Georges Didi-Huberman no seu Atlas. ${ }^{2}$

Como diria Walter Benjamin: "Não existe tarefa mais importante para a história da arte que a de decifrar as profecias, o que nas grandes obras do passado Ihe conferia valor à sua época da sua redação." ${ }^{3}$ Pelas imagens, existe uma tarefa de ler o presente diante daquilo que é intransmissível. Feito esse quadro para entendermos até que ponto as imagens podem ser entendidas como a pele do mundo, seguimos aos limites da figura humana, onde esse embate conheceu seu ápice com a invenção da perspectiva e com o apogeu da figura humana. Quanto à questão da forma, a figura humana perdeu os seus

\footnotetext{
2 DIDI-HUBERMAN, Georges. Atlas, Como llevar el mundo a cuestas? Madrid: Reina Sofia, 2010, p. 29.

3 BENJAMIN, Walter. Paralipomènes et variantes de l'œuvre d'art à l'époque de sa reproduction mécanisée (1936). In: Écrits Français. Trad. J.-M. Monnoyer. Paris: Gallimard, 1991, p. 180 apud CARERI, Giovanni; DIDI-HUBERMAN, Georges. L'histoire de l'art depuis Walter Benjamin. Paris: Editions Mimesis, 2015.
} 
contornos, e daí surge a composição híbrida de uma paisagem onde os três grandes reinos, animal vegetal e mineral, são convocados a se modificarem com o que era humano a partir de profecias. Na história dos estilos sabemos que o maneirismo criou uma dobra possível para o acontecimento do barroco e os detalhes das formas viventes passaram a ornamentar o ambiente de um modo distinto. Isso não é apenas uma questão da arte sob o prisma inabalável do estilo, mas um modo de pensar a organização própria dos objetos e das imagens que dialogam entre si e que desses encontros resultam imagens outras que solicitam um novo texto ou outro ponto de vista para serem, assim, narradas. Resta desenvolver uma ideia manifesta de pele, existente aqui como uma pele do mundo que muda justamente pelas imagens e que ganha opacidade a partir desse caráter intransmissível de cada época.

Qual seria então o ponto de vista para observar como o mundo se representa? Um dos caminhos possíveis seria lançar um olhar aos mapas para perceber toda a noção gráfica de um mapa. Isso implica que não necessariamente devemos ser cartógrafos no sentido matemático, geométrico e geológico, mas que podemos entender essas erosões, acidentes ou tremores de terra a partir de textos e de imagens. Podemos dizer que os mapas se ocuparam da superfície da terra, contornando-a de modo rigorosamente geométrico em termos de longitude e latitude. Afastando, inclusive, as imperfeições do planeta, as irregularidades que fazem com que realmente a esfera de um globo terrestre não coincida com a superfície do planeta e que muito menos seja redonda. Essa é uma construção que deriva do geógrafo italiano Franco Farinelli, em $A$ invenção da terra. ${ }^{4}$ A cosmografia, ao longo da história, tornase geografia, fruto do método ptolomaico de projeção de cálculos astronômicos para o plano bidimensional. ${ }^{5}$ Talvez certa noção epidérmica facilitasse a localização de viajantes, sobretudo quando o mundo se torna uma superfície, pois, afinal, precisamos do mundo esférico e plano. Nesse sentido o ensaio de Luiz Costa Lima, "História e Literatura", adota Humboldt como um parâmetro importante para abolir o "sublime" da natureza, para trazer clareza aos relatos de viajantes que, antes dele, derivavam ao fluxo incontrolável da imaginação. Com Humboldt temos a exatidão descritiva e o efeito estético no texto de um viajante. $^{6}$

\footnotetext{
${ }^{4}$ FARINELLI, Franco. A invenção da terra. Trad. Francisco Degani. São Paulo: Phœbus, 2012.

${ }^{5}$ Ver precisamente "A terra é uma cabeça". Ibidem, p. 59-64.

${ }^{6}$ LIMA, Luiz Costa. História e Literatura. In: Terra Ignota. A construção de Os sertões. Rio de
} 
Convém recuperar uma nuance nesse processo de distinção entre seres que se localizam que assume cada vez mais uma precisão inabalável, a de que o mapa também possui suas origens animais, sendo que o primeiro mapa como manifestação gráfica foi impresso sobre uma pele de cervo, levando em consideração o "mapa pisano", cerca de 1296 d.C., que era uma reunião de instruções. ${ }^{7}$ A partir dessas duas informações, a ptolomaica e a de um mapa primário, podemos nos perguntar com uma devida distância da ciência o que é um mapa? Se recorremos ao seu étimo, a palavra charta, simplesmente chegamos à constatação que ele é uma "folha de papel". Todavia, a geo-grafia não se fundirá por completo com o que André Leroi-Gourhan distinguia entre a "voz-audição" e a "mão-gráfica", exatamente como Gilles Deleuze e Félix Guattari nos fazem observar no Anti-Édipo. Essa geo-grafia deixou seus traços impressos sobre essa relação entre voz e audição sobrevivente na pele do animal que foi suporte para esse mapa.

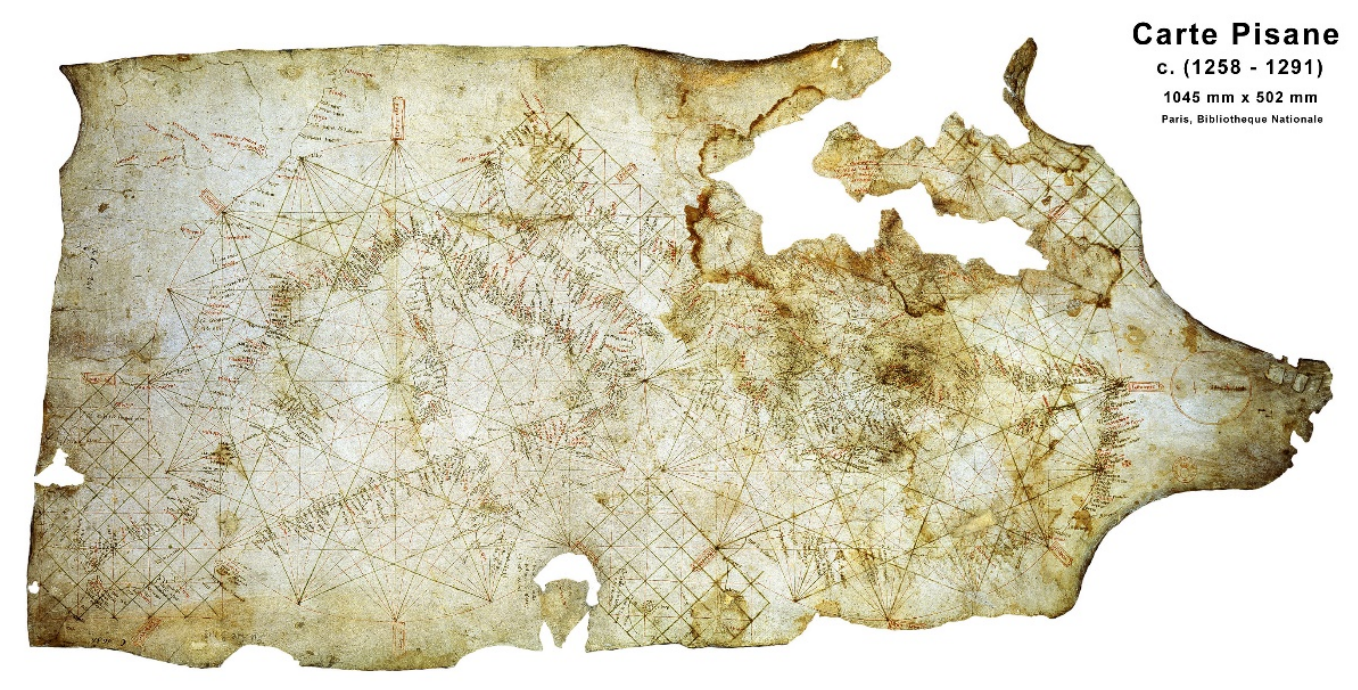

FIGURA 1 - CARTE PISANE

Embora a origem constelar ateste as coordenadas dos mapas, existe um grau de distância com o que estará presente na voz-audição sobre a mão-gráfica. Por esse aspecto, concordamos com Deleuze e Guattari quando eles

Janeiro: Civilização Brasileira, 1997, p. 221.

7 CRESQUES, Abraham. Le plus ancien portulan occidental: Carte dite pisane. In: L'Atlas Catalan. Paris: BnF, ca. 1290. [1 feuille vélin ms, 502 x 1045 mm. Rés. Ge B 1118]. 
elaboram uma nuance a partir da distinção de Leroi-Gourhan, a saber, que as formações selvagens orais e vocais não dispensam um sistema gráfico, pois ele sempre está presente: "uma dança sobre a terra, um desenho na parede, uma marca sobre o corpo." ${ }^{8}$ Esse é o grau ficcional por onde o movimento metamórfico das imagens perpetua sua transmissão de uma força plástica vinda da terra: per monstra ad astra. ${ }^{9}$ Alteração feita por Aby Warburg da locução latina Per aspera ad astra, que significa a passagem dos caminhos mais difíceis em direção às estrelas. Dos monstros, a terra se exprime por uma força plástica, pela ausência de cálculo. Isso nos prepara para a abertura geográfica do saber ou, melhor, para uma aventura geológica do não-saber.

A esses gráficos e a esses monstros podemos acrescentar ainda os delírios dos viajantes, os erros de rota, os naufrágios e todos os imaginários advindos dos bestiários bastante difundidos ao longo da Idade Média que sobreviveram sob o signo do monstruoso, do telúrico e das imperfeições da terra, do fantástico e dos gestos de catalogação que se proliferaram na América Latina, pois nessa direção ao sul os cruzamentos da imaginação com o real proliferaram o surgimento de outros seres ao longo desses mapas. ${ }^{10} \mathrm{O}$ termo mapa parece abandonar sua condição exclusivamente geo-gráfica, pois, afinal, escritores, artistas, aventureiros, todos buscaram os lugares infra-ordinários dos mapas, partindo do princípio de uma promessa de bens materiais, de riqueza, de outra forma de vida e com isso, eles mesmos contribuíram para a alteração das escalas, redimensionando seu aspecto gráfico, sua escuta e, assim, as rotas nele impressas. Por outro lado, esses mapas temporários, efêmeros, parciais não deixam de apresentar os traços de povos autóctones capazes de se orientar pelas cascas de árvore ou pelos rastros de sangue animal. Esses mapas precários destinados à desaparição emprestam seus traços a uma infinidade de mapas imateriais, inscrevendo no próprio ideário de mapa experiências de acúmulo e de abandono.

\footnotetext{
${ }^{8}$ DELEUZE, Gilles; GUATTARI, Felix. Capitalisme et schizophrénie. L'Anti-CEudipe. Paris: Editions de Minuit, 1972, p. 222. [Critique].

9 DIDI-HUBERMAN, Georges. Dialektik des Monstrums ou la contorsion comme modèle. In: L'Image survivante. Histoire de l'art et temps des fantômes selon Aby Warburg. Paris: Editions Minuit, 2002, p. 286-287.

${ }^{10}$ Sobre esse aspecto, permitimo-nos fazer uma referência à pesquisa: OLIVEIRA, Eduardo Jorge de. Manuais de zoologia. Os animais de Jorge Luis Borges e Wilson Bueno. Dissertação (Mestrado em Teoria Literária), Faculdade de Letras, Universidade Federal de Minas Gerais, Belo Horizonte, 2009.
} 


\title{
EXPERIÊNCIAS DE ACÚMULO E ABANDONO: A CONSTRUÇÃO DA AUSÊNCIA
}

O acúmulo e o abandono imediatamente diz respeito à ideia de representação por uma relação entre a terra e o mapa. A terra, sua matéria, seu relevo acidentado e sua condição geológica, conta ainda com toda sua força de "voz-audição", bem mais próxima das evidencias dos signos da animalidade. O ocultamento da terra - a terra enterrada por uma habilidade gráfica rigorosa - enfatiza a construção de uma ausência. Entre ambas as situações, existem as marcações temporais, as expansões da terra na sua dimensão física. No entanto, a construção do abandono igualmente pode ser rigorosa e, por esse rigor, Jorge Luis Borges, através de uma breve narrativa, "Del rigor en la Ciencia" assinala a busca de precisão de uma escola de cartógrafos:

\begin{abstract}
... En aquel Imperio, el Arte de la Cartografía logró tal Perfección que el mapa de una sola Provincia ocupaba toda une Ciudad, y el mapa del Imperio, toda una Provincia. Con el tiempo, esos Mapas Desmesurados no satisficieron y los Colegios de Cartógrafos levantaron un Mapa del Imperio, que tenía el tamaño del Imperio y coincidía puntualmente con él. Menos Adictas al Estudio de la Cartografía, las Generaciones Siguientes entendieron que ese dilatado Mapa era Inútil y no sin Impiedad lo entregaron a las Inclemencias del Sol y de los Inviernos. En los desiertos del Oeste perduran despedazadas Ruinas del Mapa, habitadas por Animales y por Mendigos; en todo el País no hay otra reliquia de las Disciplinas Geográficas. ${ }^{11}$
\end{abstract}

Suárez Miranda: Viajes de varones prudentes, Libro Cuarto, Cap. XLV, Lérida, 1658.

"Del rigor en la Ciencia" foi publicado em 1960 em uma reunião intitulada El hacedor em uma parte que se chama "Museo". Essa narrativa tinha sito publicada anteriormente em Los Anales de Buenos Aires, Ano 1, No 3, Março de 1946. Nessa ocasião o texto tinha por título "Museo" e era assinado por B. Lynch Davis, o pseudônimo de Borges com seu amigo Adolfo Bioy Casares. Nesse texto existe uma atuação da voz-audição sobre a mão-gráfica, um conflito que torna inútil um mapa na escala 1 (E 1:1). O real, finalmente, ou a terra - para ser mais preciso - atua sobre o mapa que fisicamente sofre as condições geológicas que determinam suas ruínas e seus novos habitantes.

A possibilidade do mapa se configurar como ruína ou como pele morta,

\footnotetext{
${ }^{11}$ BORGES, Jorge Luis. El Hacedor. In: Obras completas 2. Buenos Aires: Emece, 2010, p. 339.
} 
abre os caminhos para uma segunda saída da representação. Se a primeira tinha sido a figura humana, retorcida pelo estilo ou pela maneira, a segunda seria o próprio mundo. Essa abertura nos leva a uma outra experiência de acúmulo e abandono, o que pode nos mostrar, com esse ponto de partida de um texto de Borges, uma obra, uma exposição, ações de artistas e uma quantidade exaustiva de textos literários que, sobre essas superfícies, constroem outras e, sob o signo da errância, da migração e da construção de lugares temporários, constroem outras superfícies, mapas cada vez mais efêmeros, cuja informação gráfica pode se condensar em um gesto. Esse é o signo da ficção que habita os mapas e que produzem uma nova camada para o mundo. Tal movimento nos é sugerido por Raúl Antelo, em Ausências, quando ele escreve com a força de uma equação que "a ficção extrai o sentido do praesens, a partir do absens das imagens que ela mesma coordena, monta e dispõe para o nosso uso". ${ }^{12}$

A partir da proposição de Antelo, leremos alguns momentos da obra do artista Nelson Félix (Rio de Janeiro, 1954) que apresenta uma obra capaz de tencionar o corpo e o espaço pelo viés das coordenadas geográficas. Partir da coordenada e não da paisagem, eis o objetivo do artista. Nelson Félix faz da geografia uma fonte ficcional do espaço, como acontece em Concerto para encanto e anel (2005-2009) ao fazer uma cruz imaginária na América do Sul. Nelson Félix encontra o centro dessa cruz em um pequeno vilarejo na Bolívia chamado Camiri, lugar que intitula a exposição realizada em 2006 no Museu da Vale, no Espírito Santo. Para o artista, existe uma dimensão estrutural na obra, onde com a escala desmedida existe uma construção da forma de modo não-presencial. ${ }^{13}$ Tanto as coordenadas quanto as quarenta toneladas de ferro possuem um peso nessa obra, o que faz com ele negue o aspecto ficcional. A ficção, no entanto, estaria no dispositivo discursivo que reúne aço, mármore e as coordenadas geográficas. Se preferirmos, poderíamos dizer, para retornar ao texto de Costa Lima sobre Humboldt, que o artista retira o sublime da natureza. Ao passar o acontecimento desta obra no espaço expositivo, Rodrigo Naves faz uma descrição da composição feita pelo artista no galpão do Museu da Vale:

Num grande galpão, são dispostas 27 vigas de ferro paralelamente ao plano do

\footnotetext{
${ }^{12}$ ANTELO, Raul. Ausências. Florianópolis: Editora da Casa, 2009, p. 5.

${ }^{13}$ Conversa com o artista no dia 6 de agosto de 2015.
} 
chão, a pouco mais de um metro de altura (para ser mais preciso, no nível dos olhos do artista). A partir da última viga, seguem-se doze outras traves de ferro dispostas numa inclinação de 23 graus em relação ao corpo do galpão. A última dessas vigas atravessa um grande anel de mármore de 2,32 metros de diâmetro. No seu interior repousam dois outros anéis, menores. ${ }^{14}$

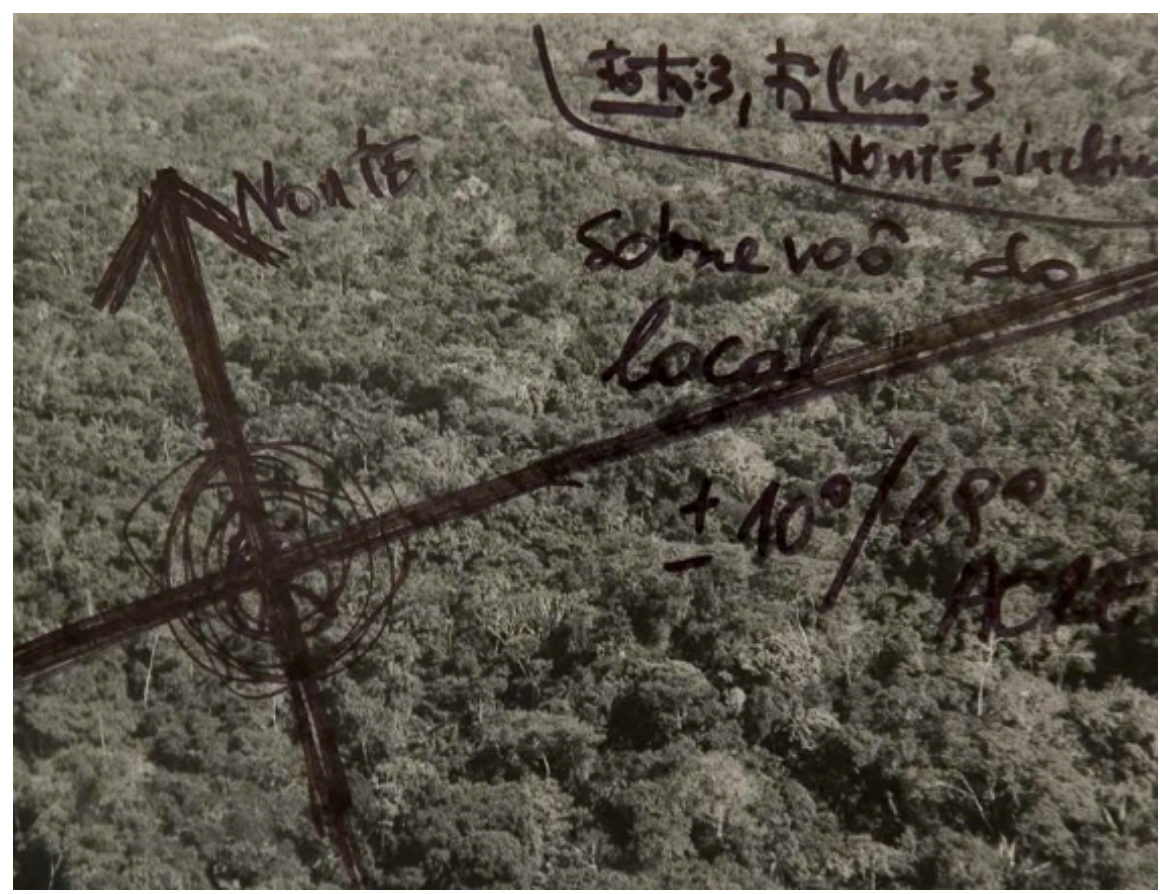

FIGURA 2 - CRUZ NA AMÉRICA DO SUL

A descrição de uma obra, eis um lugar para iniciar uma ficção e criar um ponto de abandono capaz de decepcionar um historiador da arte. A partir da matéria escolhida pelo artista, sua composição no espaço, derivamos pelo seu aspecto ficcional, sua força narrativa e sua sustentação textual. A enumeração dos materiais (Ferro e mármore Carrara), a disposição no espaço (o galpão do Museu) e a composição com a qual o artista se posiciona ligada às coordenadas geográficas vindas de uma cruz traçada no mapa (Cruz na América) formam uma história criada pelo artista, um exercício de meditação em termos de desenho e uma reconstituição de um mapa na América Latina onde a cruz seria um marco zero. Ferro e mármore, viga e anel, enfim uma matéria que ressalta algo intransponível vindo de uma temporalidade da arquitetura, do mito das cidades modernas (ferro) à transcendência no renascimento (már-

\footnotetext{
${ }^{14}$ NAVES, Rodrigo. Nelson não mora mais aqui. In: FELIX, Nelson. OOCO. São Paulo: Pinacoteca, 2015, p. 82.
} 
more). A forma obedece a uma outra escala, onde boa parte dela não está visível, exigindo, assim, um trabalho mental, uma ficção vinda do espaço, da cruz e sua ausência, do pequeno povoado na Bolívia chamado Camiri e na sua enunciação musical que também mantém uma proximidade serial com a sua remontagem nas Cavalariças, no Parque Lage. Precisamente nessa obra, Concerto para encanto e anel, Nelson Félix procurou prever, até certo ponto, os acontecimentos da matéria, a partir de um espaço cartografado, para lidar com um tempo que contorna a pele gráfica do mapa.

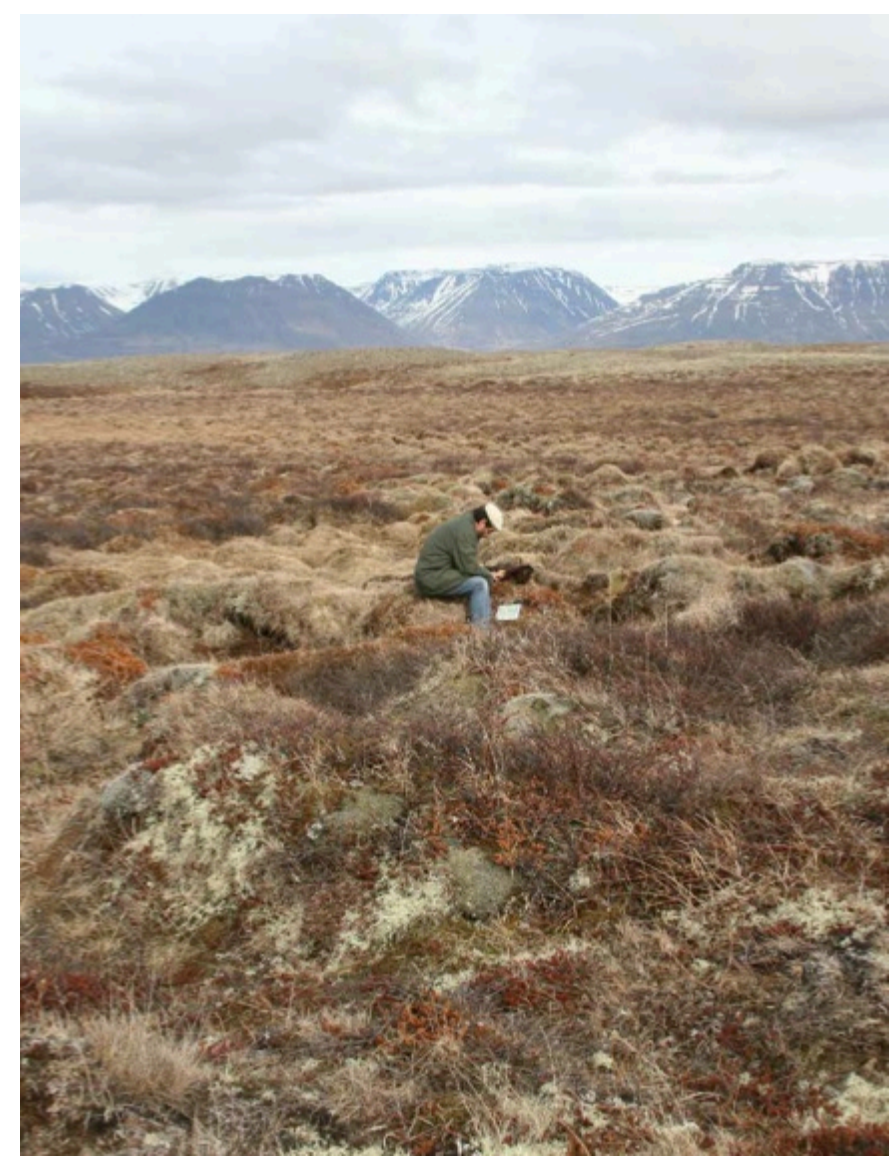

FIGURA 3 - HEKLA

O que fica em evidência no Museu é a estrutura parcial do trabalho. Esta mesma que será novamente montada de outra forma, por intermédio de uma série de ações escultóricas que o artista faz ao redor do mundo, pois o concerto segue pelo vulcão Hekla, na Islândia, mas também por outros pontos como o Caribe, Dongsha, ainda na Islândia e Karratha, na Austrália, no deserto de sal, na Bolívia. A obra sobrevive em suas variações. Os elementos presentes 
nesses lugares, em mármore italiano e em ferro, ora sobrevivem sob a forma de imagem fotográfica, ora movem-se de modo mais contínuo pela ficção que sustenta a obra, aquilo que poderíamos chamar de um concerto para o final da máquina do mundo camoniana já desmontada inicialmente por dois poetas no Brasil: Carlos Drummond de Andrade ("A máquina do mundo") e Haroldo de Campos ("A máquina do mundo repensada").

A partir de Nelson Félix, chegamos ao corpo do espaço, isto é, um corpo ausente e ficcional presente em uma verdadeira lição de anatomia dos mapas também feita pelo artista. A percepção da passagem do corpo para o espaço pode ser percebida a partir de um comentário de Nuno Ramos, quando este, ao se indagar sobre o aspecto do corpo na obra de Nelson Félix, admite a forte presença do corpo em Tarsila do Amaral, em Hélio Oiticica e Lygia Clark e, claro, além desses artistas uma corporeidade assumida na arte brasileira. Félix responde a Ramos que, a partir da biblioteca do pai, que era médico, ele começou a querer ler o corpo. O gesto de ler o corpo, abstraí-lo provavelmente em mapa ou mais precisamente em pele fez com que o artista fosse para o espaço inventar situações. Ao revisitar as anotações, esboços, esquemas e desenhos que o artista torna público em seus catálogos, entendemos a necessidade que ele tem de pensar processos de expansão lentos, contidos nos corpos de indígenas brasileiros ou de mulheres na Birmânia que utilizam expansores para os lábios e para o pescoço. E com isso ele lida com a contradição fundamental aqui pensada entre a cultura e natureza, onde, na verdade não há contradição.

Nelson Félix lidou com os equívocos da cultura, a partir de uma forma de viver com o próprio corpo. ${ }^{15} \mathrm{E}$ com esse corpo, o artista sentiu na pele os limites da floresta, mais precisamente na amnésia que um território organizado politicamente tem com suas margens. Ao realizar outra obra como o Grande Bhuda, de 1985, no Acre, ele não apenas sentiu "na pele a coisa"16 ao entrar na floresta, mas fez da coisa, a pele. A floresta passou a ser a pele do artista, seu modo de sentir o espaço. Ele também anota que a árvore entra em um processo de adaptação para retornar em objeto cultural. O nível dessa observação é antropológico, o limite da antropologia física com a cultural.

\footnotetext{
${ }^{15}$ NAVES, Rodrigo. O que me interessa é essa coisa indefinidamente sugestiva. In: Nelson Félix. São Paulo: Cosac Naify, 1998, p. 44.

${ }^{16}$ Depoimento retirado da entrevista dada a Glória Ferreira. FERREIRA, Glória. Domínios, dimensões, escalas. In: Entrefalas. Porto Alegre: Zouk, 2011. p. 157.
} 


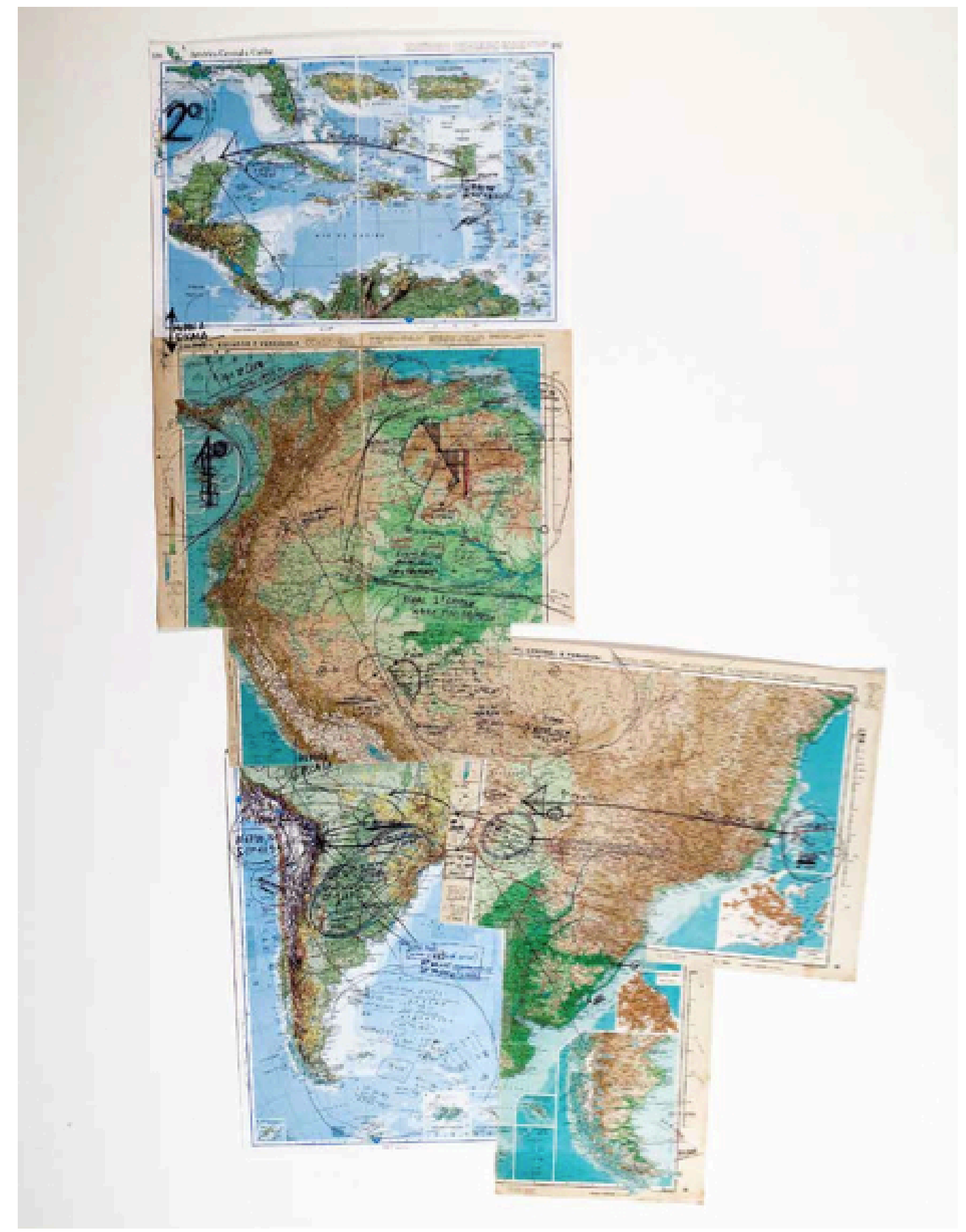

Todavia, essa aproximação antropológica é suplementar ao exercício espiritual que o artista almeja. Com essa dimensão espiritual da existência de um trabalho em um dos confins do Brasil, a sua narrativa mantém a dimensão virtual fora de um espaço expositivo como um museu. Mas o fora do museu, como aconteceu em Camiri, é uma estratégia para inserir o espaço expositivo 
em uma coordenada geográfica. Com isso, o lugar coincide - geograficamente - com a situação. Em meio ao tempo circular proposto pela estrutura dos anéis em Carrara, Nelson Félix compõe uma elipse. Ronaldo Brito precisa a elipse feita pelo artista, onde a viagem participa e sustenta a escultura:

\begin{abstract}
À falta de um verbo adequado, digamos, soma-se a isso o deslocamento do artista até Camiri, pequena aldeia no interior da Bolívia, em função de sua (quase) perfeita correspondência com a situação geográfica do museu em Vila Velha: encontram-se a 23 graus um do outro, sobre a mesma latitude no globo, os mesmos 23 graus de inclinação em que a Terra gira ao redor do eixo do Sol. A operação escultórica, bastante concreta, que envolve o espaço do museu e a viagem casual mas esteticamente compulsória do artista, deslocando-se a Camiri, constituem, portanto, a forma aberta do trabalho. ${ }^{17}$
\end{abstract}

O museu concretiza-se em coordenada geográfica. A forma aberta do trabalho a qual se refere Brito é a ambivalência da sustentação pelo nome de uma pequena cidade na Bolívia ou o esquecimento da composição, sua exclusão voluntária da vida e do ambiente para destinar-se unicamente a ser um objeto para ser visto em uma determinada exposição. Em todas essas ações, o que se sustenta é uma parte ausente que se torna fundamental para a dinâmica do desenho em Nelson Félix. Tais ações têm o desenho por princípio e um alto grau de imprevisibilidade, onde há uma consciência da condição perene das imagens. Ou pelo menos, material. Mas onde elas, as imagens, seriam perenes? Em "Da cor do amarelo", Nelson Félix escreve que "as imagens adquirem um poder de perenidade e, embora estando no presente, ultrapassam o momento e chegam mesmo ao diálogo entre culturas geográfica e historicamente diferentes." ${ }^{18}$ Isso posiciona uma escala que sai do espaço para o tempo, participando do tempo da narrativa.

A perenidade das imagens, todavia, depende de um ritmo interno inerente às trocas materiais entre essa separação espácio-temporal ou, para expressarmos esse aspecto com Aby Warburg, elas se traduziriam nos "valores expressivos pré-formados." ${ }^{19}$ Existindo uma herança na memória dos povos, o que não pode ser apagado pelas curvas geométricas da cartografia porque

\footnotetext{
${ }^{17}$ BRITO, Ronaldo. Corrigir pelo erro. In: FELIX, Nelson. OOCO, op. cit., p. 142. Agradecemos vivamente a Júlia Ayerbe o acesso ao catálogo da exposição de Nelson Félix.

${ }^{18}$ Ibidem, p. 101.

${ }^{19}$ WARBURG, Aby. Introdução à Mnemosine. In: Histórias de fantasmas para gente grande. Trad. Lenin Bicudo Bárbara. São Paulo: Companhia das Letras, 2015, p. 365.
} 
elas também são frutos de um estudo detido dos astros. A mão do artista participa da perenidade das imagens ao elaborar novas imagens, que implicam em gestos atravessados pelo desenho, como acontece ao longo das obras de Nelson Félix. Ainda em "Da cor do amarelo", Félix tem a consciência do desabrochar de imagens nas mais diversas ocupações, nas festividades e nos momentos de diversão, o que inclui o espetáculo, atos públicos, competições esportivas e mesmo a burocracia e a propaganda, sem excluir a literatura. Isso compreende os mapas, os deslocamentos, as migrações e as viagens, locais onde essas trocas se realizam. Em meio a esses fatores, há uma estrutura que possui um valor pré-formal que facilita a transmissão das imagens, pelo rumor e pela lenta construção do tempo controlado parcialmente pelo artista. $\mathrm{Na}$ América, mais ao sul, a máquina do mundo é identificada, repensada, abandonada. Os mapas perdem suas escalas nas mais breves narrativas, nos esboços e desenhos, a ausência é um fenômeno plástico e até fenomenológico e a filosofia continental permanece selvagem, com uma atenção ao que as imagens apresentam em termos de profecias. 